\title{
Cultures of Tort Law in Europe
}

\author{
by
}

Ken Oliphant*

\begin{abstract}
This article provides a short introduction to the present special issue of the Journal of European Tort Law, which critically investigates the cultures of tort law in four selected national or regional contexts in Europe: England, France, Germany and Scandinavia. It explains what is meant by the idea of a culture of tort law, summarises the articles that follow, and ends with some concluding reflections from a comparative perspective.
\end{abstract}

(2012) 3 JETL 147

This special issue of the Journal of European Tort Law investigates critically the cultures of tort law in four selected national or regional contexts in Europe: England, France, Germany and Scandinavia. ${ }^{1}$ The aim is, in a modest way, to give a rounder understanding of tort in the different legal systems than is possible if one looks only at formal legal rules, by investigating the broader set of attitudes, practices, experiences, institutions and values that together make up its culture. The papers that follow this introduction address these topics for each of the chosen jurisdictions in turn, and are the basis for the short comparative observations offered below. The authors have been at pains to stress that their ambition is limited to throwing a few rays of light on selected aspects of their subject matter, rather than providing a comprehensive and fully theorised account.

This is a field of study that is still in its infancy, and it is hoped that this special issue - notwithstanding its necessary limitations - will be found a useful addition to the literature and a stimulus to further research in the area.

* Director, Institute for European Tort Law, Austrian Academy of Sciences; Professor of Tort Law, University of Bristol. This and the following articles are revised versions of lectures given at the 11 th Annual Conference on European Tort Law on 14 April 2012 in a special conference session on Cultures of Tort Law in Europe.

1 For illuminating earlier analyses, see $C$ van Dam, European Tort Law and the Many Cultures of Europe, in: T Wilhelmsson (ed), Private Law and the Cultures of Europe (2007); id, Who is Afraid of Diversity? Cultural Diversity, European Cooperation and European Tort Law (2009) 20 King's Law Journal 281. 


\section{The idea of a culture of tort law}

The title 'cultures of tort law' makes a conscious reference to the large literature addressing the idea of 'legal culture' generally. ${ }^{2}$ However, no specific conception of 'legal culture' is presumed here, and contributors were encouraged to take a broad view of what it refers to, and to approach it in the way they personally considered most illuminating of their own systems. As a starting point, however, it may be suggested that tort law's culture embraces, but is not necessarily limited to, the following:

1. Societal attitudes towards tort law. This includes (adapting Lawrence Friedman) 'the attitudes, values and opinions held in society with regard to [tort] law, the [tort] system and its various parts' 3 and invites consideration of how popular attitudes towards tort are affected by the media, ${ }^{4}$ political discourse, and public interventions by stakeholders (eg insurers, business and victim-support organisations).

2. The practice of tort law ('what tort lawyers do'), referring to 'the informal norms and expectations that regular players in the system (lawyers and judges) have come to accept as "how we do things"' in tort claims, ${ }^{5}$ including 'inarticulate premises which are culturally and historically ingrained in the professional discourse and outlook.' 6

3. The practical experience of those involved in tort claims - what Friedman famously called 'the lived experience of the law'; ' this addresses the question of what makes people claim, ${ }^{8}$ as well as the impact of tort law and the tort process on claimants and defendants, and those more remotely involved (eg family members).

4. Tort law's institutional context - how the principles of tort law and their application are affected by other institutions (eg insurance, social security).

2 See eg J Gibson/G Caldeira, The Legal Cultures of Europe (1996) 30 Law \& Society Review (L \& Soc Rev) 55; D Nelken, Defining and Using the Concept of Legal Culture in: E Örücü/D Nelken, Comparative Law: A Handbook (2007) 109, 113; M Van Hoecke/ $M$ Warrington, Legal Cultures, Legal Paradigms And Legal Doctrine: Towards A New Model For Comparative Law (1998) 47 International and Comparative Law Quarterly 495.

3 L Friedman, The Legal System: A Social Science Perspective (1975) 76.

4 Cf W Haltom/M McCann, Distorting the Law (2004).

5 Gibson/Caldeira (1996) 30 L \& Soc Rev 55, 56.

6 M Hunt, The Human Rights Act and Legal Culture: The Judiciary and the Legal Profession (1999) 26 Journal of Law \& Society 86, $87 \mathrm{f}$.

7 Friedman (fn 3).

8 See especially W Felstiner/R Abel/A Sarat, The Emergence and Transformation of Disputes: Naming, Blaming and Claiming (1981) 15 L \& Soc Rev 631; A Morris, Spiralling or Stabilising? The 'Compensation Culture' and our Propensity to Claim Damages for Personal Injury (2007) 70 Modern Law Review (MLR) 349. 
5. The cultural values embedded in substantive tort law - how the purposes of tort are conceived, and how fundamental issues of tort law principle are resolved (eg the balance between fault-based and strict liability, the breadth of interests protected, how damages are assessed).

It will be apparent from the above that the culture of tort law encompasses 'the law in action' as well as 'the law in the books', the attitudes, behaviour and experiences of ordinary people as well as those of legal elites, the deep structures of the tort system as well as its surface features, and what is taken for granted and overlooked as well as what is made explicit in standard accounts.

\section{The contributions to this special issue}

To achieve the designated goals, it was necessary to engage contributors who combined in-depth 'native' knowledge of the legal systems in question with an ability to take a step back so as to subject their own preconceptions and acquired beliefs to critical analysis. Ideally, they would be from outside of 'the mainstream', somewhat iconoclastic in their approach, and have the comparative methodological tools to identify and highlight what an outsider might find most interesting about their system. Fortunately, each of the contributors recruited for this special issue possesses all of these qualities in abundance.

\section{A. France}

Jean-Sébastien Borghetti begins his contribution on the culture of French tort law (responsabilité civile extracontractuelle) with the observation that its well known victim-oriented approach has not wrought the havoc in France's economy and society that one might have expected. He finds that at least part of the explanation is cultural. Addressing first the context of French tort law, Borghetti notes that public awareness of the tort process (especially of damages awards) appears rather limited. Tort law issues are rarely a matter of public debate, and there is none of the concern with 'compensation culture', the burdens faced by potential defendants, or the possible withdrawal of goods, services and public amenities through fear of litigation risk that is to be found in some other countries. Borghetti finds that this quality of inconspicuousness is largely a function of the prevalence of liability insurance and the substantial social security benefits available to accident victims independently of their right to compensatory damages in tort. Only rarely (eg in some high profile medical cases) is concern expressed even about increases in insurance premiums consequent on developments in liability law.

9 J-S Borghetti, The Culture of Tort Law in France (2012) 3 JETL 158. 
This lack of public interest in tort law in France means that its culture is largely synonymous with that of its 'key players', amongst whom Borghetti specifically highlights legal academics, judges and attorneys. He emphasises that legal academics specialising in tort law form a very small and largely homogenous group - some 30 to 40 in number - whose dominant victim-oriented ideology reflects the strong Christian and humanist values of some of its leading members. Few have practical experience of the law outside academia. The emphasis on dogmatics in their training, and the lack of any interdisciplinary component, also accounts for a certain homogeneity in the dominant academic mode of reasoning, which Borghetti describes as 'positivistic' insofar as, when confronted with a new decision, academics generally ask how it can be justified, and not whether it is correct. Obviously, there are exceptions. Borghetti concludes by looking at the role of judges and attorneys, whose mentality he finds to be strongly influenced by their academic education and by academic writing. There are some points of contrast, however - for example, the Cour de cassation's abstention from the definition of central concepts like fault and causation so as not to tie its hands in later cases, and the tendency towards precedent-based reasoning amongst practising lawyers. In Borghetti's provocative but thoughtful account, these paraxodical features are typical of French tort law generally - institutionally embedded in society yet publicly invisible; dogmatically committed to principle yet casuistic.

\section{B. Germany ${ }^{10}$}

For Jörg Fedtke, the challenges of writing about the culture of German tort law are encapsulated in a remark made by the great Austrian comparative lawyer Ernst Rabel: 'Everything in the social, economic and legal fields interacts. The law of every developed people is in constant motion, and the whole kaleidoscopic picture is one which no one has ever clearly seen'. ${ }^{11}$ Rabel's words are simultaneously a reminder of the need to see law as a constantly evolving and complex interaction of multiple factors, both legal and extralegal, and a warning that any description of it can only be partial. Fedtke's own account of German tort law begins with the law in action, and specifically the question: are Germans especially litigious? The statistical data suggest they are not. Numbers of filed civil claims are lower per capita than, for example, in the UK or US. The focus of such concern as the system attracts is the workload of the courts rather than 'compensation culture' - as evidenced by recent legislative efforts to promote mediation as an alternative to litigation. Conversely,

10 J Fedtke, The Culture of German Tort Law (2012) 3 JETL 183.

11 E Rabel, Aufgabe und Notwendigkeit der Rechtsvergleichung (1925) 3 (translation from H Kötz, Comparative Law in Germany Today, Revue internationale de droit comparé (RIDC) 4-1999, 753 (756)). 
the extraordinary popularity of legal expenses insurance (the German market alone accounts for $45 \%$ of gross premium income in Europe) illustrates the 'uncertainty avoidance' that may be seen as a general German trait - as is amusingly if anecdotally confirmed by Fedtke's reference to blog posts on a forum for Germans who have moved to the UK. This, and the moderate cost of litigation in Germany, are two possible reasons for the high numbers of small claims that are brought.

In the rest of his paper, Fedtke tracks the impact of social change on the judicial interpretation of the tort provisions of the German Civil Code (Bürgerliches Gesetzbuch, BGB) since it came into effect in 1900. In that period, the country has experienced perhaps unparalleled upheaval, and no fewer than six very different 'Germanies' have existed: Empire, the Weimar Republic, the Third Reich, the former East and West Germanies, and the current reunified state. On its legislative face, tort law has remained largely constant, but the textual stability of the 'Big German Book' obscures the subtle evolutions that have occurred in the meanings attached judicially to its terms, for example, as a result of the constitutional protections introduced after the horrors of the Nazi period and the strong commitment to human rights thereby entailed. He also highlights the powerful influence of social security, whose impact has been the transformation of personal injury law from a compensation mechanism to a device for shifting costs between public and private insurance institutions: 'The dispute thus loses its personal dimension and turns into a fairly standardised business transaction between professional bodies. ${ }^{12}$ Where tort retains a compensatory function is in respect of non-pecuniary loss, which social security does not cover, but the conservative approach of the courts to the quantum of awards is another factor opposing the development of any compensation culture. Overall, Fedtke's wide-ranging but subtle analysis demonstrates the key role the courts have played in creating modern German tort law culture as one component part of the wider legal and social system.

\section{Scandinavia ${ }^{13}$}

Håkan Andersson's approach is to trace developments in the discourse of Scandinavian tort law over the last century through a set of historical 'stopovers' at 20-year intervals. Each comes with its own soundtrack in the form of a set of listening recommendations illustrating the broader intellectual climate of the period.

Andersson's account begins some 100 years ago with the birth of the intellectual tradition called Scandinavian Realism. Like other contemporaneous

12 Fedtke (2012) 3 JETL 182, 201.

13 H Andersson, The Tort Law Culture(s) of Scandinavia (2012) 3 JETL 210. 
movements in philosophy, this denounced the application of evaluative language to human interactions as mere metaphysics, but it had a stronger commitment to the fulfilment of societal needs than other schools. This translated into a legal science that rejected ideas of blame, interpersonal justice and rights. In tort, though the traditional language was retained, the decisive question became 'who ought to bear the risk?' rather than 'who was at fault?'. Tort came to be seen as one mechanism amongst many for dealing with the social problem of accidental personal injury, and not the most important. Collective approaches based on private and/or social insurance were preferred, with tort playing at best only a supplementary role. To this day, the same philosophy is institutionally embedded in tort law in Scandinavia. Social security benefits are deducted from the damages payable for personal injury, and there is no right of recourse against the tortfeasor; the social security system is left to bear the full cost. The same also applies to collective insurance taken out by private parties (eg employers). In any case, special no-fault insurance schemes covering personal injury suffered at work, in a traffic accident, in the course of medical treatment and from the use of pharmaceuticals mean that individual claims against the tortfeasor are superfluous in practice in these contexts, even if notionally available. In Denmark and Norway, the supplementary role of tort law is further emphasised by the exclusion of liability for property damage and pure economic loss that is covered by private insurance, except in cases of intentional conduct or gross negligence.

In recent decades, greater scepticism towards social welfare goals, and their attainment through legal mechanisms, has been reflected in a change in the discourse of tort law from 'grand narratives' of progress to a multitude of 'small stories'. The latter are the product of an academic approach to tort law that focuses on particular issues and consciously abstains from adopting any unifying vision of tort's ultimate purpose, though in some of its forms it embraces and seeks to further ethical goals - for example, the promotion of solidarity against the exercise of coercive power. In Andersson's view, the rights-based accounts of tort law that have recently attained prominence in Scandinavia should be viewed as just one more of these 'small stories', rather than - as their proponents would advocate - a new paradigm. He nevertheless submits that a critical engagement with 'rights' and ideas of justice can assist in the further development of tort law to meet society's needs, with considerations of welfare and risk allocation reflected in the definition given to such terms. The pragmatic tradition of Scandinavian Realism cannot be written off just yet! 


\section{The United Kingdom ${ }^{14}$}

Two contrasting images of tort law in the UK provide the framework for the contribution to this special issue by Richard Lewis and Annette Morris. Each in its own way is quite misleading. The first is the idealised image of tort law taught to law students, presupposed in legal practice, and projected in judicial utterances: tort involves the even-handed application of universal principles of justice; personal injury claims in tort are fundamentally about real people; claims are adjudicated in the courts; liability is largely dependent on proof of fault and findings of law; the resolution of claims reflects the requirements of due process and fairness; tort law is especially concerned with serious injuries and significant financial needs; losses suffered are compensated in full.

Skilfully demonstrating that each of these propositions involves a misperception of the reality of tort law in action, the authors draw upon the extensive empirical data that is available on the personal injury claims system in the UK. Despite tort law's notional universality, certain types of injury tend to attract compensation in practice while others do not, reflecting the incidence of liability insurance. The names of individual litigants appear in the law reports but real control over the claims process lies with the insurers who cover the defendant's liability and - where there is legal expenses ('before-the-event') insurance - determine how the claimant should be represented. The most important centres of personal injury practice are not the courts but - because over $98 \%$ of claims are settled before trial - insurance company offices. In practice, insurers rarely dispute liability, so fault and legal concepts like the duty of care and proximate cause are not as central to the tort system as standard accounts make them appear. Claims are settled by the application of rules of thumb that reduce handling costs; claimants benefit when fault is presumed in their favour, but the system overall is weighted in the interests of insurers and results in considerable inequality. Very few damages awards are for serious injuries; most involve relatively small sums, with non-pecuniary loss accounting for approximately two thirds of the overall damages bill. Even when the seriously injured do receive damages, the amounts awarded often fail to attain the purported goal of full compensation because unduly optimistic assumptions are used in their calculation.

The authors' second image of tort law portrays it in terms of the damaging 'compensation culture' constantly bemoaned by politicians and the media in the last decade. Its alleged consequences are risk-averse behaviour by potential defendants, detrimentally affecting the public at large, and a general decline in notions of personal responsibility. These effects are attributed by some to expansions in the scope of tortious liability in recent decades, and dilution

$14 R$ Lewis/A Morris, Tort Law Culture in the United Kingdom: Image and Reality in Personal Injury Compensation (2012) 3 JETL 230. 
of the fault principle to which the British are (supposedly) culturally tied, and to others attributed by changes in the wider claims environment - especially the introduction of 'no win no fee', and aggressive advertising by new entities known as claims management companies (CMCs). As the authors show, the evidence that a compensation culture exists is mostly anecdotal and is not borne out by the statistical data on claims, which show that numbers have actually diminished in many categories in the relevant timeframe. One category in which claims numbers have shown a marked increase, however, is personal injury resulting from a road traffic accident, which now accounts for some $80 \%$ of all personal injury claims. The authors suggest that three interrelated factors may be at play: the sophisticated systems introduced by CMCs to discover the names and contact details of those involved in road accidents so they can be encouraged to claim; the routinisation and streamlining of claims-handling processes; and the financial attractiveness of motor claims to 'no win no fee' providers of legal services.

Overall, the authors convincingly debunk many of the myths that surround the UK's tort system today, opposing them to a 'reality' that is itself an extremely interesting social phenomenon.

\section{Some concluding observations}

It would be impossible to provide a full analysis of the tort law culture of any single legal system within the confines of a single journal article (or even a much longer contribution). The unavoidable limitations of any such analysis are multiplied if one seeks to compare accounts of tort law culture in different legal systems. All that can result is - to use some of the metaphors employed by contributors to this special issue - a patchwork or collage of images, a kaleidoscopic vision that changes every time one looks at it. However, this introduction would be incomplete if it did not attempt to highlight, if only briefly, at least a few common themes emerging from the articles that follow.

\section{A. Tort law cultures - plural}

The first is that there is not one single tort law culture in a given legal system, but several. These include at least the following: the culture into which students of tort law are indoctrinated as part of their education; the cultures of the practitioners, judges and academics they become; the cultures of the big non-legal institutions (especially liability insurers and social security providers) that play a large role in the overall system; and the cultures of tort law projected by politicians and the media and reflected in popular consciousness. Some of these groups are rather small and homogenous, yet have a powerful influence on how 
tort law is perceived by others. (Consider, for example, the influence of the 30 to 40 academics specialising in tort law in France.) Each has a legitimate claim to inclusion in any full account of what tort law is as a social phenomenon.

\section{B. Tort's institutional context}

Secondly, as has just been mentioned, the practice of tort law is very strongly influenced by its institutional setting and the attitudes and behavioural norms of big institutional actors - especially in personal injury cases. Perhaps the two most powerful of these influences are insurance and social security. Almost all defendants are insured against their liabilities, and almost all damages - in the UK, an estimated $94 \%$ of the total for personal injury - are paid by insurance. How claims are resolved in practice thus turns on the strategies adopted by liability insurers - reflecting bureaucratic considerations of cost and administrative efficiency as well as (arguably, more than) strict legal entitlements. Where the claim is brought by an individual, how the liability insurer exploits the undoubted inequality of bargaining power between them is another determinative factor. The extent to which the individual's interests are protected by the acquisition of effective legal representation - and the role played here by legal expenses insurance - are further components of tort law's institutional context that contribute to its culture.

The other big institutional actor to consider is social security. All the countries covered by this special issue have well-developed welfare states, which cover the medical needs of accident victims and compensate for their losses at what are, in international comparison, relatively generous levels. In France and Scandinavia, in particular, this welfare provision is complemented by a variety of no-fault compensation schemes that are applicable in specific spheres (eg road traffic accidents and medical injuries). This has a profound impact on the dynamics of the tort process insofar as personal injury claims are concerned. In most cases, the injured person's needs will be fully covered independently of tort law, so it is simply unnecessary to bring an action for damages. From the victim's perspective, tort's role is limited to the 'topping up' of the welfare benefits provided. As the latter do not cover pain and suffering, compensation for non-pecuniary loss is given disproportionate emphasis in litigated claims. But-largely invisible to the public at large, and even to the injured person - tort law continues to operate behind the scenes, providing social welfare agencies with rights of recourse against tortfeasors (France, Germany) or reimbursement from compensation payments at source (UK). The extent to which recourse rights are exercised in practice remains to be fully uncovered, but one noteworthy practice that has developed in Germany (and perhaps elsewhere) is for social welfare agencies to enter into bulk agreements with liability insurers by which they undertake not to exercise their rights to recourse in return for the 
reimbursement of a certain proportion of their expenditure in defined categories of case. This reinforces a theme which emerges from all the papers in this collection: that tort law is only one part of a wider personal injury compensation system in which claims lose their personal dimension and become standardised business transactions between institutional actors.

\section{The values embedded in tort law}

Lastly, the articles that follow this introduction shed interesting light on the values embedded in tort law in the different legal systems selected for comparison. There is a striking contrast between the self-consciously victimoriented approach taken in France and Scandinavia, strongly emphasising loss distribution, and the rather conservative conception of tort prevailing in the UK. There, the accent is more on corrective than on distributive justice evidenced by the retention of fault-based liability even for motor accidents - and, at least in the public debate around 'compensation culture', the interests of potential defendants seem often to come first. Where France and the Scandinavian countries differ is in the balance struck between liability in tort and general welfare provision as compensatory mechanisms for accidental injury. In France, tort law is primary - at least on paper - insofar as it provides for rights of recourse against the tortfeasor for social security and (with some exceptions) the special compensation funds. Though most defendants are covered by liability insurance, the costs of accidents are still allocated to the class of those engaging in risky activities. Loss distribution is achieved through particularly broad strict liabilities backed by widespread liability insurance. In Scandinavia, by contrast, no-fault insurance - not strict liability - is the preferred approach, and the no-fault and social security schemes are funds of last resort. They have no recourse against the tortfeasor and so effectively provide a 'subsidy' for tortfeasance. Accidental injury is seen as a social problem requiring a coordinated societal response and direct public expenditure.

How German tort law should be characterised within this analytical frame is a more difficult question to answer. In very loose terms, Germany occupies a position mid-way along the spectrum that places the UK at one end and France and Scandinavia at the other. The victim-orientation of the latter jurisdictions is not so apparent: other than for road accidents, strict liability is rather limited in scope; with the exception of work accident insurance (workers' compensation), there is little no-fault provision for personal injuries. On the other hand, the public concern evident in the UK about the excesses of 'compensation culture' is largely absent. If pressed to encapsulate the German conception of tort law, one might reach for 'managerial' as the most appropriate label, indicating a preoccupation with legal rules and procedures that best ensure the cost-effective resolution of disputes. The terminology also 
gives a hint of the largely unpoliticised environment in which tort law operates in Germany - in contrast with the UK. Some evidence for the characterisation of German tort law as managerial can be found in the level of recent concern about excessive judicial workloads, the consequent promotion of mediation to divert claims from the courts, the detailed statutory rules about lawyers' remuneration, and the bulk agreements concluded between social security agencies and liability insurers. The characterisation also provides some support for the contention that strict liability for motor accidents was introduced less for reasons of justice to victims than because of the need to find an efficient mechanism to resolve an ever-increasing mass of claims. ${ }^{15}$ Of course, there are many features of German tort law that do not fit the description, but that simply brings us back to points that were made above: there exists a plurality of tort law cultures in every jurisdiction, and no single perspective can capture every significant aspect.

\section{$*$}

With those cautionary words in mind, readers are now invited to explore the four analyses of tort law culture in selected European legal systems that make up the main part of this special issue. It is hoped that they will discover in them new perspectives on how tort law is conceived, perceived, practised and experienced in different parts of the continent, and be encouraged to explore for themselves new ways of looking at its various cultures, whether in Europe or elsewhere.

15 See W Ernst, Introduction, in: id (ed), The Development of Traffic Liability (2010) 7. 